\title{
Cognitive-behavioural treatment for workers with chronic spinal pain: a matched and controlled cohort study in Sweden
}

\author{
I B Jensen, Å Nygren, A Lundin
}

\begin{abstract}
An ambulatory multimodal cognitivebehavioural treatment programme (MMCBT) for Swedish workers with chronic spinal pain was formally evaluated. The design was a matched cohort study with three repeated measures done in two groups of $\mathbf{3 5}$ referred patients (one exposed to MMCBT and controls exposed to usual care). The MMCBT package includes standardised modules of physical treatment, cognitive-behavioural treatment, education of worker patients, and education of subjects' supervisors. The primary outcome variables assessed were absenteeism, disability, pain, and depression. Because of a change in Swedish sick leave compensation laws affecting records of absence during the study period, absenteeism could not be reliably measured among controls. The trend, however, suggested a reduction of absenteeism among the subjects in the MMCBT cohort. The findings for disability, pain, and depression all showed clinically important and significant beneficial changes (ANOVA for repeated measures: disability $p=$ 0.05 ; pain $p=0.001$; depression $p=$ $0 \cdot 01)$. The direction of the improvements and the size of effect were coherent and clinically plausible. The benefits were only among the women in the study. These comprised $74 \%$ of each group. Further research on larger sample sizes and in cohorts more representative of the whole country are needed to confirm these encouraging findings and to explore how the benefits might be extended to men.
\end{abstract}

(Occup Environ Med 1994;51:145-151)

Department of personal injury prevention, Karolinska Institute, Stockholm I B Jensen A Nygren

NärRehab, HälsoInvest i Örebro, Sweden

A Lundin

Requests for reprints to: Dr I B Jensen, När Rehab, Halso Invest i Örebro, Ribbingsg 1-3, 70363 Örebro, Sweden.

Accepted 17 May 1993 the long term quality of life of individual subjects and families. ${ }^{1}$ Virtually nothing is known about primary prevention or about the pre- pain is becoming more prevalent in many western countries and, increasingly, is costly both socially and economically. Several The Quebec Task Force on Spinal Disorde devastating effects that chronic spinal pain vention of pain becoming chronic. A new development in the past 10 years has been the introduction of treatments for chronic spinal pain syndromes that are based on a cognitive behavioural approach. Such intervention programmes have been shown to be effective, particularly in the management of pain. ${ }^{34}$

Multimodal cognitive-behavioural treatment, including physical components, has also been developed in Sweden in recent years. Typically, in the past, the therapeutic programmes have been in inpatient settings and the clinics are located geographically distant from the patients' everyday environment. ${ }^{56}$ (And Jensen et al, unpublished data.) Other models of intervention, such as the well known Swedish Back School, have been almost exclusively educational depending on didactic classroom teaching without specific techniques of behavioural change. The passive approach in the Back School strategies might explain the disappointing results when they have been evaluated. ${ }^{7}$ Even though the outcomes in some evaluative studies have shown positive results these tend to decline after six and 18 months of follow up. ${ }^{4}$ (And Jensen et al, unpublished data.) Important factors in cognitive-behavioural intervention are the maintenance programmes that aim to prevent relapses and protect initial gains. We speculate that the declining gains of treatments developed in Sweden are partly explained by the lack of opportunity for patients to practice their newly acquired skills in their daily environment. Lack of opportunity and lack of maintenance programmes may be the keys affecting long term results. Other factors associated with the maintenance of initial improvement in perceived pain and in residual impairment are compliance and social support available in the surroundings where the behavioural changes are intended to take place (Jensen et al, unpublished data).

We report a study wherein we evaluated an outpatient treatment programme designed for long term neck, shoulder, and back pain of employed persons, which was based on cognitive behavioural theory. A distinctive feature of the strategy was that the workplace supervisors of the employees were taught to reinforce the behavioural changes of employed patients. The interventions evaluated in this study included a one day training course for the patients' supervisors within the main training programme for the patients, which lasts four weeks. Thus one objective of the project was to augment the supervisors' 
understanding of pain and to teach them how to reintegrate employees who had participated in a cognitive-behavioural programme of rehabilitation. The purpose of the study was to assess the effectiveness of multimodal cognitive-behavioural treatment by measuring physical and psychological endpoints among patients.

\section{Methods}

GENERAL PLAN OF THE STUDY

This study compares two small cohorts of 35 subjects each. The cohorts were formed by matching non-referred controls to referred patients by criteria listed later. Another cohort of 88 patients, including 53 who could not be successfully matched, were used as a reference to monitor bias. The two cohorts were contrasted, having been measured three times each.

As we did not assign the subjects to treatment and control groups this prospective study is non-experimental or observational. Nevertheless, the groups assembled for comparison proved to be similar.

\section{DESCRIPTION OF INTERVENTIONS}

The treatment consists of five modules: physical treatment, cognitive behavioural modification, education, promotion of patients' interaction with their usual occupational and social situation, and training of work supervisors to enhance reintegration to the job.

\section{PHYSICAL TREATMENT}

Physical treatment emphasises selfadministered care and is designed to enhance endurance more than strength. Specifically, it includes progressive training with machines for physical training and specially designed gymnastic exercises aimed to improve the function of the neck, shoulders, and back. Leg muscles and abdominal muscles are also targets. More natural and spontaneous physical activities such as walking in the forest, bowling, swimming, cycling, and badminton are also strongly promoted and practise under observation is part of the programme. Optionally, the physical therapists can use their clinical judgement and give traditional manoeuvres such as passive exercises, ultrasound, heat, massage, and others.

THE COGNITIVE-BEHAVIOURAL MODULE

The cognitive-behavioural module consists of eight sessions where problem solving, goal setting, acquisition of skills (stepwise goal fulfilment), and relaxation applied to each patients' life context (applied relaxation) are taught and practised under supervision. During the treatment period a contract was developed and consisted of goals of behavioural changes to enhance health promoting behaviour and pertained to all the modules, not just the cognitive-behavioural module. The latent goal of the cognitive-behavioural module is to enable patients to perform all new skills learnt without supervision in their home and work settings and to induce a sus- tained change of health-illness behaviour through a procedure that rewards and reinforces positive change (also known as operant technique). In the skills acquisition component, the patients have homework that is individually tailor made to each person's problem solving and goal setting. The cognitive-behavioural module sessions follow a predetermined standardised plan. (Available upon request from I B Jensen.)

THE EDUCATIONAL MODULE

The educational module involves all categories of professionals and clinicians of the interdisciplinary team: psychologist, physician, nurse, and physical therapist. It consists of 12 lectures that consider anatomy, the nature of stress, the use and effect of medications, pain behaviour and its consequences, cognition, the dynamics of psychosomatic responses, and the consequences of overstimulation or understimulation of the body and the psyche. All lectures are followed by small group sessions where the participants discuss the issues raised in class and answer questions about them in writing. Spouses or others are invited to all lectures particularly to the ones about pain driven behaviour.

INTERACTION OF THE TREATMENT TEAM WITH THE PATIENTS' MEDICAL, OCCUPATIONAL, AND SOCIAL SUPPORT NETWORK

Specifically this important interaction involves one or more of the referring physician, a human resources officer (personnel department) of the employer, an occupational counsellor, a representative of a governmental social insurance authority. The purpose of this module is to exchange information about the patient and to acquaint relevant people in the patient's environment of the individualised goals of the treatment programme developed and adopted by the patient. Thus it becomes possible for all persons involved in the reintegration of the patients to be confluent with them in pursuing exactly the same goals.

\section{TRAINING OF PATIENTS' SUPERVISORS}

Training of supervisors is, in our view, a critically important module orientated to smooth reintegration of the subjects to their employment. It is a one day session offered in two parts: in the morning the supervisors hear an intense and concentrated synopsis of the educational syllabus that the patients themselves will have learned; in the afternoon, they are taught rehabilitation planning, which incorporates the techniques of problem solving and goal setting taught to the patients. They then have to practise the techniques through simulated problems of the work environment prepared specifically for them. Supervisors have an opportunity to meet the patients in the clinic that day and discuss common concerns.

All the modules described become an integrated and interdependent package (MMCBT). Apart from the individualisation of each patient's goals and the principle of 
discretion in clinical judgement of the physiotherapists there is no deviation from patient to patient. Accordingly, the MMCBT as a whole is the intervention under assessment in this study (independent variable) although in later analyses we will examine selected modules in isolation, notably the supervisors' role.

\section{STUDY SUBJECTS}

There were 101 patients originally referred to an outpatient facility in the south east of Sweden called NärRehab/Hälsoinvest (NRH) located in the centre of the city of Örebro. Patients were referred primarily by the governmental social insurance authority (Försäkringskassan) and by physicians practising occupational health. The patients were all from the Örebro area, drawn from a catchment not more than $50 \mathrm{~km}$ from the city limits. Eight patients refused to participate. Five patients were referred with insufficient information to establish their eligibility. Eighty eight subjects were eligible. Table 1 shows available data on non-participants.

\section{CRITERIA OF ELIGIBILITY FOR PATIENTS AND \\ MATCHING PROCEDURES FOR CONTROLS}

All subjects in the study were first screened before being assigned to the patient group in the MMCBT programme or to the group of matched controls. The screening process comprised a standardised and documented history and physical examination by an orthopaedic surgeon, a functional assessment by a physical therapist, and a psychological evaluation by a registered psychologist. Eligibility criteria were then applied. The same three specialists examined all patients and controls. Informed written consent was obtained from all participants after an explanation of the treatment and of the study to each patient. The orthopaedic surgeon and the physical therapist were also part of the team that administered the MMCBT programme. A different psychologist was in the treatment team than the one who screened for measured outcome variables.

\section{PATIENTS' INCLUSION CRITERIA}

Inclusion criteria included, (1) Pain located in the neck and shoulder, or vertebral column (either dorsal or lumbar or both). (2) Diagnosis of "non-specific pain syndrome" without objective neurological signs (confirmed in all patients at the NRB rehabilita-

Table 1 Characteristics of refusers, ineligible patients, and losses to follow up

\begin{tabular}{|c|c|c|c|}
\hline & $\begin{array}{l}\text { Refusers } \\
(n=8)\end{array}$ & $\begin{array}{l}\text { Ineligible } \\
(n=5)\end{array}$ & $\begin{array}{l}\text { Losses to follow up } \\
(n=4)\end{array}$ \\
\hline $\begin{array}{l}\text { Age (mean; y) } \\
\text { Women }(n)\end{array}$ & $\begin{array}{r}45 \\
7\end{array}$ & $\begin{array}{r}36 \\
2\end{array}$ & $\begin{array}{r}38 \\
3\end{array}$ \\
\hline $\begin{array}{l}\text { Occupation(n): } \\
\text { Unskilled blue collar }\end{array}$ & & & \\
\hline $\begin{array}{l}\text { Unskilled blue collar } \\
\text { Skilled blue collar }\end{array}$ & 1 & 1 & 1 \\
\hline Unskilled white collar & 1 & - & - \\
\hline Skilled white collar & - & & 1 \\
\hline $\begin{array}{l}\text { Topography of pain(n): } \\
\text { Neck and shoulder }\end{array}$ & 5 & 2 & 2 \\
\hline Dorsal and lumbar & 1 & 2 & - \\
\hline Mixed pain & 2 & 1 & 2 \\
\hline
\end{tabular}

tion clinic by the same orthopaedic surgeon as part of the screening procedures). (3) Age 20-55. (4) Fluent in the Swedish language. (5) Currently employed. (6) On full or partial leave of absence (sicklisted) for six months or less.

It is important to stress that shoulder pain was never in isolation.

\section{CRITERIA USED FOR MATCHING}

A list of all concurrently sicklisted workers in the Orebro area was available from the social insurance authority. We sought to pair all 88 eligible patients to an eligible control. The matching criteria were: (1) age, plus or minus five years; (2) currently employed; (3) broad category of work (unskilled blue collar including manufacturing, craftsman, service and care, white collar, academics); (4) location of pain and diagnosis that excludes neurological signs; (5) about the same amount of time on sick leave.

We located 48 pairs but at least one member of five of the pairs became ineligible (for example, through new diagnoses or lost employment). Eight controls refused to participate (table 1). Refusers tended to be unskilled blue collar workers who had neck and shoulder pain.

\section{BLINDING}

For insurmountable logistic reasons, it was not possible to blind the measuring psychologist to whether study subjects were patients or controls. As there were at least twice as many patients in the MMCBT programme than in the study, the treating clinicians were, however, never sure which of the patients in their classes or groups were being measured for purposes of controlled evaluation.

\section{MEASUREMENT OF DEPENDENT VARIABLES}

There were two categories of endpoints that were dependent variables-namely priority endpoints and explanatory variables. The priority endpoints were selected before the analysis was begun and so were absenteeism, physical functional capacity, pain intensity, and depression. The explanatory variables were anxiety, perceived helplessness, and coping strategies. In this paper we report primarily the findings of the priority endpoints. Explanatory variables are only discussed when illuminating but will be reported in detail in a subsequent report. The detailed analyses of the explanatory variables are available on request.

Target variables used as endpoints were assessed at baseline, before treatment, at the end of treatment (about four weeks after baseline), and at six months of follow up.

\section{ABSENTEEISM}

Details on leave of absence were obtained from the national health insurance (NHI) authority for one year before the treatment and for six months afterwards. The main comparisons made before and after treatment were possible for the same six month period before treatment and the same six month 
follow up period. Moreover, total absenteeism was the hardest variable used. It is noteworthy that in Sweden all employees are covered by the national insurance scheme. Regulations require that both the employer and the insurance authority must be notified by the end of the same business day of the absence so that benefits can be received. That means that virtually all absences are on record. Employees also can be absent for a full or a part of a day due to illness. Accordingly absenteeism was recorded in hours rather than days.

\section{PAIN INTENSITY AND ANXIETY}

These data were recorded in a diary by the patients for seven days leading up to the time of the other tests. Pain intensity and anxiety were recorded three times daily (morning, noon, and evening) on a $100 \mathrm{~mm}$ visual analogue scale (VAS). High score indicates higher pain/anxiety level.

\section{DEPRESSION}

We used the Beck depression inventory. ${ }^{8}$ Scores range from $0-60$ with the higher scores more severe.

\section{DISABILITY}

This 12 item self administered questionnaire with semantic differential questions measures patients' satisfaction with their ability to perform daily activities (for example, walking and dressing). It is the Swedish version of the Health Assessment Questionnaire, and we found it to be reliable and valid. ${ }^{9}$ Scores range from 0-60; higher means less satisfaction with functional disability.

\section{PERCEIVED HELPLESSNESS}

The 15 item measure of perceived helplessness is the Swedish version of the arthritis helplessness index, ${ }^{10}$ slightly modified to focus on neck, shoulder, and back pain. It requires subjects to rate the extent to which they believe they can control the consequences of pain. It is self administered. A high score indicates a high level of perceived helplessness (range 0-48).

COPING STRATEGIES

This was a Swedish version of the coping strategies questionnaire with 48 items ${ }^{11}$; scores range from 0-36 for each of eight strategies

Table 2 Selected sociodemografic variables

\begin{tabular}{lcll}
\hline & $\begin{array}{l}\text { Controls } \\
(n=35)\end{array}$ & $\begin{array}{l}\text { Matched patients } \\
(n=35)\end{array}$ & $\begin{array}{l}\text { Reference group } \\
(n=88)\end{array}$ \\
\hline $\begin{array}{l}\text { Age (mean, (SD) } \\
\text { Female(\%) }\end{array}$ & $44(9 \cdot 2)$ & $43(8 \cdot 8)$ & $40(9 \cdot 5)$ \\
$\begin{array}{l}\text { Married(\%) } \\
\text { Number of children } \\
\text { (Mean, (SD)) }\end{array}$ & 74 & 74 & 74 \\
$\begin{array}{l}\text { Occupation(\%): } \\
\quad \text { Unskilled blue collar }\end{array}$ & 60 & 89 & 77 \\
$\quad$ Skilled blue collar & $2(0 \cdot 72)$ & $2(0 \cdot 77)$ & $2(0 \cdot 80)$ \\
$\quad \begin{array}{l}\text { Unskilled white collar } \\
\text { Skilled white collar }\end{array}$ & 37 & 37 & 36 \\
$\begin{array}{l}\text { Workers compensation: } \\
\quad \text { claim(\% yes) }\end{array}$ & 6 & 43 & 41 \\
$\begin{array}{l}\text { Unfinished } \\
\text { workers compensation(\%): }\end{array}$ & 66 & 23 & 22 \\
\hline
\end{tabular}

reviewed. Higher scores indicate greater use of the particular strategy concerned.

\section{CONTRASTS AND ANALYSES}

For the priority endpoints, the most important contrast is between the 35 patients who were matched successfully and their respective 35 controls. To detect bias we also compared the two cohorts of the 35 patients and the 35 controls with the reference cohort of all 88 patients by analysing them as independent samples. We did no tests of significance in the second set of comparisons; it was done to find bias and for descriptive purposes only. Parametric paired statistics were used in the main contrast. To assess the trends in the data over time we used analysis of variance with repeated measures. ${ }^{12}$

\section{Results}

SIMILARITY OF COHORTS COMPARED

Table 2 shows that the two main matched cohorts compared and the reference cohort of all patients are sufficiently similar in their sociodemographic characteristics at baseline to enable comparisons of the effect of the intervention. Data in table 3 show that they are also similar in respect to the clinical and explanatory variables measured initially.

\section{NON-PARTICIPANTS}

Table 1 suggests that there was no major selection bias in excluding subjects from the cohorts with the possible exception of a somewhat greater high refusal rate among unskilled blue collar workers.

\section{PRIORITY ENDPOINTS}

Table 4 presents the principal findings of this study. The means of the four outcomes selected before the start are shown for the baseline measurements, and for the two follow ups (at four weeks, and six months). The means for the within pair differences from baseline to each follow up are also shown. We show all patients as the reference cohort to

Table 3 Explanatory and clinical variables at baseline

\begin{tabular}{|c|c|c|c|}
\hline & $\begin{array}{l}\text { Control } \\
(n=35)\end{array}$ & $\begin{array}{l}\text { Matched } \\
\text { patients } \\
(n=35)\end{array}$ & $\begin{array}{l}\text { Reference } \\
\text { group } \\
(n=88)\end{array}$ \\
\hline \multicolumn{4}{|c|}{$\begin{array}{l}\text { Participated in rehabilitation } \\
\text { programme (\% of controls) } \quad 34\end{array}$} \\
\hline $\begin{array}{l}\text { Mean duration of pain } \\
\text { (months) }\end{array}$ & 44 & 37 & 45 \\
\hline \multicolumn{4}{|l|}{ Topography of pain: } \\
\hline Neck and shoulder(\%) & 20 & 11 & 18 \\
\hline Dorsal and Lumbal (\%) & 0 & 6 & 11 \\
\hline Mixed pain (\%) & 80 & 83 & 71 \\
\hline Spinal mobility (median) & 98 & 90 & 90 \\
\hline Neck mobility (median) & 329 & 280 & 290 \\
\hline Global self rating (mean) & 3.4 & 3.6 & $3 \cdot 8$ \\
\hline Perceived helplessness (mean) & $26 \cdot 6$ & $27 \cdot 1$ & $27 \cdot 2$ \\
\hline Anxiety (mean) & $20 \cdot 1$ & 21.6 & $23 \cdot 4$ \\
\hline \multicolumn{4}{|l|}{ Strategies for coping (mean): } \\
\hline Diverting attention & $12 \cdot 7$ & $12 \cdot 0$ & $12 \cdot 1$ \\
\hline Reinterpreting pain & $5 \cdot 1$ & $3 \cdot 1$ & 3.4 \\
\hline Coping self statement & $16 \cdot 3$ & $15 \cdot 9$ & $16 \cdot 2$ \\
\hline Ignoring sensations & $13 \cdot 2$ & $12 \cdot 1$ & $11 \cdot 7$ \\
\hline Praying and hoping & 11.5 & 10.8 & 11.5 \\
\hline Imagining catastrophy & 11.5 & $11 \cdot 8$ & 12.0 \\
\hline Increasing behavioural & $15 \cdot 7$ & $14 \cdot 2$ & $15 \cdot 0$ \\
\hline Pain behaviours & $17 \cdot 3$ & $16 \cdot 2$ & $16 \cdot 4$ \\
\hline
\end{tabular}


Table 4 Priority endpoints at baseline (BA) after treatment (4 weeks) and at follow up ( 6 months) (means and means of differences within pairs)

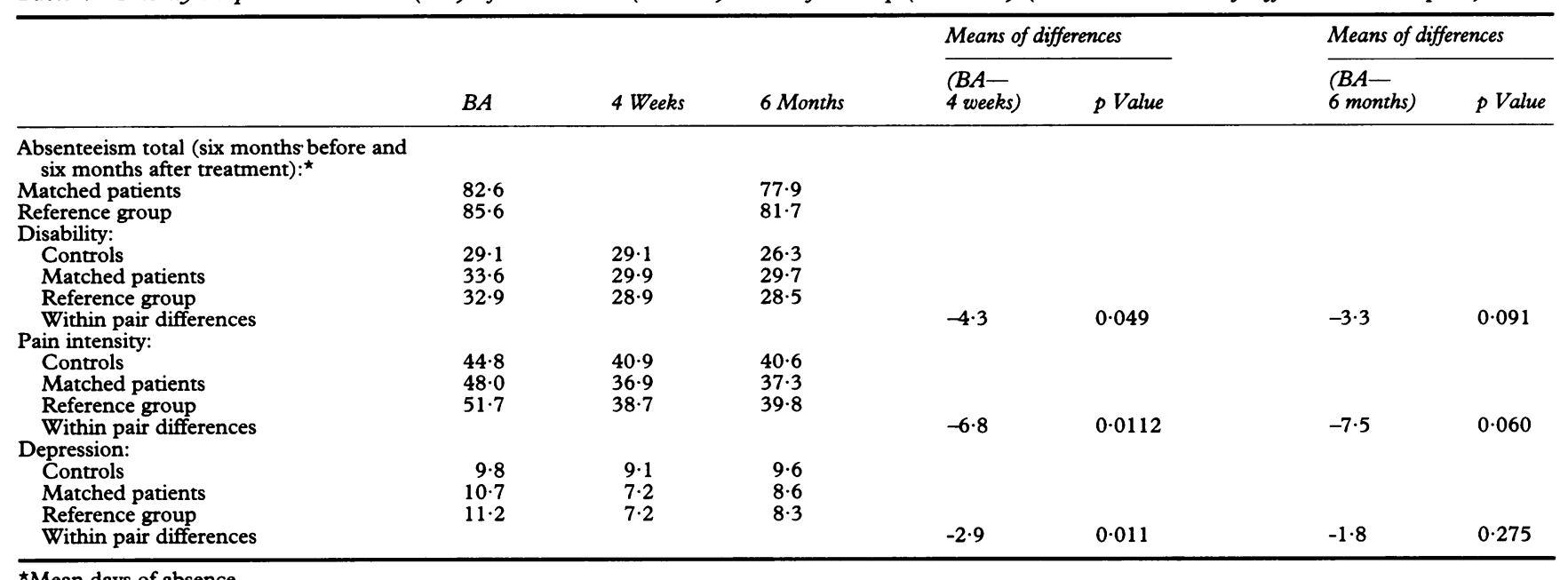

$\star$ Mean days of absence.

insure that the patients we succeeded in matching were not unrepresentative of all the patients referred and entered in the MMCBT programme. For all four endpoints the three cohorts are similar at baseline.

During the time from when the field work began until the end of record linkage at the NHI authority one year later (August 1992) the sick leave data were altered by changes in Swedish legislation. Since January 1992, the government is no longer responsible for short term sick leave. Instead, employers record and pay for the first 14 days of absence due to sickness and all such short term sick leave had only to be reported to the NHI authority. It was soon discovered, however, that employers neither recorded nor reported and thus the NHI authorities data base was missing up to $30 \%$ of its information. Accordingly, the before and after measures for the matched controls are meaningless for sickness related absenteeism. We do, however, have the before and after measures for the matched patients and the reference group of patients (table 4) after six months. The trends are towards less absenteeism and the extent to which they are sustained will be reassessed after another 12 months. For the other three outcomes that we have assessed at the first follow up an improvement is evident and is significant after four weeks for disability. Notably the improvements seem to be sustained through to the sixth month. The repeated measures analysis of variance shows that the reduction of disability over time is significant $(F=3.87 ; p=0.05)$. For pain, the difference from baseline to four weeks and to six months showed more than a $15 \%$ reduction. The trend over time again showed a sustained improvement and with repeated measures analysis of variance it was highly significant $(F=10.39 ; p=0.001)$. Depression showed an important improvement in that the patients changed from a measured mildly depressed state (Beck depression inventory score $>11$ ) to a score within normal limits (Beck depression inventory $<10$ ). The trend over time was clearly significant $(F=6.97 ; p$ $=0.01$ ).
A very important finding (despite the fact that the hypothesis was not declared in advance) showed that all the improvements seem limited to the women in the study. This phenomenon, to be reported extensively in a later paper, was characterised by both means and trends over time as significant for the $74 \%$ of subjects who were women and not at all for the men.

\section{Discussion}

Innovative treatments, such as the MMCBT programme that we adapted and standardised in Sweden, tend to be implemented with much enthusiasm but with little evaluative rigour about their effectiveness. ${ }^{34}$ That is especially true when the new approach makes clinical and common sense and deals with an intractable type of personal and social problem. The enthusiasts commonly retreat to the argument that "you can't lose!". The innovation then takes on a life of its own, attracts zealous supporters and society indeed can lose. Many ineffective treatments are costly and divert scarce resources from other more effective strategies of care, prevention, or rehabilitation. Unfortunately once a new intervention moves into the mainstream of usual care it is judged unethical to evaluate it with controlled studies. In the case of the MMCBT we were determined to do as rigorous an evaluation of the programme new to Sweden as we could soon after the MMCBT intervention was packaged and pretested in feasibility studies.

Why not a randomised controlled double blind clinical trial? Regulations and agreements between the NHI authority and our clinic do not permit us to withhold treatment from any referred patient. When we attempted to do a prereferral randomised controlled trial on eligible patients the plan was not acceptable to the authority on ethical grounds. Double blinding is not possible due to the nature of the intervention; complete single blinding became impossible because of the small budget available to engage duplicate research staff for the observations. Still 
wishing to do as good an evaluation as possible we opted for an observational comparative cohort study with the advantages afforded by it being prospective and less vulnerable to bias than other non-experimental designs such as an uncontrolled before and after study or a case control method.

We did sample size calculations but they proved to be irrelevant; we were dependent on the referral rates, refusal rates, ineligibility, and matching impossibilities within the time implicitly allotted to the study by the funding agency. Our two small matched cohorts of 35 subjects were the largest we could accrue in one year (although we assembled a total of 88 eligible referred patients who were treated and measured). To our surprise, several of the priority endpoints did show significant differences in trends over time pointing to effectiveness of the MMCBT programme despite the small sample size. Moreover, all the variables pointed in a consistent direction and with a similar size of effect. We recognise that these four outcomes are likely to be correlated. Nevertheless, our findings have clinical plausibility.

Biases can never be completely eliminated from an observational study. Yet, by design, this prospective cohort study assured that exposure to treatment was established before the outcomes could be known. Beyond that, we believe that we have minimised the biases in several ways. Firstly, the patients in the study were less than a third of the patient load of the clinic during the year of accrual and the treatment team was unaware of which patients were in the study or the matched cohort. Secondly, the patients and controls were only aware of the general purpose of the study and not the specific hypotheses. Thus they could not alter their responses to please their therapists or express animosity to anyone in any way. Thirdly, most of the data gathering was self administered so the opportunity of any information bias mediated by the evaluating personnel of the study was reduced. Fourthly, for the most important variable, absenteeism, the information was obtained by record linkage with the NHI authority's data banks. Total absenteeism thus obtained is hard data. For some of the softer data we used validated scales or questionnaires whenever possible.

External validity and the appropriateness of extrapolating this experience to all Swedish workers affected by chronic spinal pain is yet to be established. This is a promising beginning and we would not wish that clinicians or policy makers overinterpret the findings as definitive evidence that the MMCBT should be widely implemented without further evaluation or at least surveillance.

We were most encouraged that gains observed at four weeks seemed to be preserved at six months. To achieve such sustained improvement had been a central objective of our group when we designed and adapted the cognitive behavioural strategies for workers. The improvements, however, were seen only in women among our study subjects with intractable pain of the spine. We found the extent of the sex differences surprising, but sex specific effects have been described before. Lindström et $a l^{13}$ for instance, found improvements in men only in a randomised controlled trial of graded activity intervention. In other studies of health and illness women have been shown to have a more complex pattern of factors associated with selected illnesses. ${ }^{14}{ }^{15}$ (And Jensen et al, unpublished data.)

Our cohort study has some important limitations-namely, uncertain generalisable value, lack of power in instances where the differences of means were not significant, and the impossibility of setting aside completely concerns about potentially important biases in a non-experimental or observational study. Comparative cohort studies, however, are second only to randomised controlled trials in the weight that the derived evidence carries. In this evaluation we believe we have uncovered good evidence (not opinion) that an MMCBT programme for workers with chronic spinal pain can work to reintegrate them to their jobs and improve their wellbeing. To rebut this evidence would require a much larger cohort study or, preferably, an experimental controlled trial. We think that such a major study should become a research priority not only in Sweden but in other countries where occupational health research is well developed. The burden of illness, suffering, disability, and indirect, and direct costs of spinal ailments occurring in the workplace is too high for financial, regulatory, and administrative constraints to prevent an important definitive study with adequate sample size. The required investment in remodelling and refining the therapeutic intervention so that benefits might even be greater and so that observed effectiveness of the MMCBT might extend to men is also of compelling importance. This study has shown that such research can be done in the real world of the workers' environment and of the rehabilitation centre.

We acknowledge the advice given in design and analysis by Professor WO Spitzer of the Department of Epidemiology and Biostatistics of McGill University, Montreal, Canada. We also acknowledge the assistance of Irene Larsson in the collection of data. Further we thank Anders Hägg for his excellent work with the computerised data base. We graciously acknowledge that without final forsäkringar this research would not have been possible.

1 Spitzer WO, LeBlanc FE, Dupuis M. Scientific approach to the assessment and management of activity related spinal disorders. Spine 1987;12:7S.

2 Nachemson A. Ont $i$ ryggen, Statens beredning för utvärder ing av medicinsk metodik. Stockholm: SBU report, 1991.

Flor $\mathrm{H}$, Fydrich $\mathrm{T}$, Turk $\mathrm{D}$. Efficacy of multidisciplinary pain treatment centres: a meta-analytic review. Pain pain treatment

4 Corry A, Linssen G, Spinhoven P. Multimodal treatment programmes for chronic pain: a quantitative analysis of

5 Linton SJ, Bradley LA, Jensen I, et al. The secondary prevention of low back pain: a controlled study with followup. Pain 1989;36:197-207.

6 Nygren $\AA$. Áreprojektet. Rehabilitering av patienter med smärttillstånd i nacke/skuldra. Stockholm: Folksam, 1992.

7 Kamwendo K. Neck and shoulder disorders in secretaries. 
Prevalence, risk factors and neck school intervention. Lund: University of Lund, 1991. (Doctoral thesis.)

8 Beck AT. An inventory for measuring depression, Arch Gen Psychiatry, 1961;4;53-63.

9 Pincus T, Summey JA, Soraci SA, et al. Assessment of patient satisfaction in activities of daily living using a modified Stanford Health Assessment Questionnaire. Arthritis Rheum, 1983;26;1346-53.

10 Nicassio PM, Wallstone KA, Callahan LF, et al. The measuring of helplessness in rheumatoid arthritis. The development of the arthritis helplessness index f Rheumatol 1985;12:462-7.

11 Rosenstiel AK, Keefe FJ. The use of coping strategies in chronic low back pain patients: relationship to patien characteristics and current adjustment. Pain 1983; 17:33-44.
12 Roscoe JT. Fundamental research statistics for the behavioral sciences. USA: Holt, Rinehart, and Winstone, Inc, 1975.

13 Lindström I, Öhlund C, Eek C, et al. The effect of graded activity on patients with sub acute low back pain: a randomized prospective clinical study with an operant-conditioning behavioural approach. Phys Ther 1992;72: 279-93.

14 Frankenhauser $M$, Lundberg $U$, Fredrikson $M$, et al. Stress on and off the job as related to sex and occupational status in white-collar workers. fournal of tional status in white-collar workers.
Organizational Behaviour 1989;10:321-46.

15 Schumaker S, Hill RD. Gender differences in social support and physical health. Health Psychol 1991; 10:102-11

\section{Vancouver style}

All manuscripts submitted to Occup Environ Med should conform to the uniform requirements for manuscripts submitted to biomedical journals (known as the Vancouver style.)

Occup Environ Med, together with many other international biomedical journals, has agreed to accept articles prepared in accordance with the Vancouver style. The style (described in full in the BMF, 24 February $1979, \mathrm{p} \mathrm{532}$ ) is intended to standardise requirements for authors.

References should be numbered consecutively in the order in which they are first mentioned in the text by Arabic numerals above the line on each occasion the reference is cited (Manson ${ }^{1}$ confirmed other reports $^{2-5}$. . .). In future references to papers submitted to Occup Environ Med should include: the names of all authors if there are seven or less or, if there are more, the first six followed by et al; the title of journal articles or book chapters; the titles of journals abbreviated according to the style of Index Medicus; and the first and final page numbers of the article or chapter. Titles not in Index Medicus should be given in full.

Examples of common forms of references are:

1 International Steering Committee of Medical Editors, Uniform requirements for manuscripts submitted to biomedical journals. $\mathrm{Br} \mathrm{Med} \mathcal{F}$ 1979;1:532-5.

2 Soter NA, Wasserman SI, Austen KF. Cold urticaria: release into the circulation of histamine and eosinophil chemotactic factor of anaphylaxis during cold challenge. N Engl ₹ Med 1976;294:687-90.

3 Weinstein L, Swartz MN. Pathogenic properties of invading micro-organisms. In: Sodeman WA Jr, Sodeman WA, eds. Pathologic physiology, mechanisms of disease. Philadelphia: W B Saunders, 1974:457-72. 